\title{
Study on the Leisure Sport and the Sustainable Development of People
}

\author{
Houzhong Jin \\ School of Sports Economics and Management \\ Central University of Finance and Economics \\ Beijing 100081, China \\ E-mail: jinhouzhong@126.com
}

\begin{abstract}
It is the ideal that the human being assiduously seeks to make each person develop freely and completely. The development of the productivity induces that human leisure time increasingly increases and the leisure space develops gradually, so the leisure culture is more and more concerned by the academe. The ecological leisure sport is closely related with human sustainable and complete development. It should be not only the organic composing of the leisure culture study but the effective approach promoting human sustainable, harmonious and complete development to strengthen the study of ecological sports leisure and enhance human ecological quality.

Keywords: Ecological philosophy, Ecological leisure, Sports leisure, Ecological quality, Ecological civilization, Human sustainable development

In the modern time, leisure has been one of the most important characteristics. The quality of the leisure, especially for the quality of the leisure mode, will directly influence the development of the economic society, the construction of the harmonious society and the complete development of people. In this article, we first analyze the leisure definitions in foreign and domestic academe and primarily understand and standardize the essential of the leisure, and further study the close relationship between the ecological sports leisure and human harmonious, sustainable and complete development from the dimension of the ecological leisure philosophy and harmonious sports theory.
\end{abstract}

\section{Analysis of leisure definition}

The famous leisure theory expert of the Health and Human Development Academe of Pennsylvania University, professor Geoffrey Godbey thought that "the leisure is a sort of relatively free life extricating from exterior pressures of cultural environment and material environment, and it can make the individual act by his favorite mode that he will feel valuable instinctively from the interior love, and offer the base for the belief" (Geoffrey Godbey, 2000, P.14).

Professor John Kelly of US University of Illinois who was the first world leisure and amusement association research committee president thought that "the leisure is understood as a sort of "becoming status", i.e. the leisure is not the present and the practice, but the dynamic, and it includes many factors facing the future, and it is not only the existing form, situation and meaning (Johan Kelly, 2000, P.22)", and "the leisure is the main social space to complete the human and social development, and it is a sustainable and important development stage in the whole life of people (Johan Kelly, 2000, P.104)". Taking human healthy status as the example, human healthy status is decided by human daily living mode, leisure behavior, emotion and luck. Except for good inheritance from parents, the most important decisive factors of the human health include individual habit, daily behavior and collective action. If people keep good nutrition, persist in sports training and cultivate healthy habit, so human average life will be prolonged much longer (Geoffrey, 2000, P.133).

The famous scholar who first put forward the leisure culture theory in China is Yu Guangyuan. In early 1983 , Mr. Yu put forward that though China emphasized the sports competition, but the researches about the competition and game except for sports were not enough. In Chinese higher colleges, there is no one course studying the game, there is no one specialty of game, and there is no one scholar to study the game. In July of 1994 when he gave lectures in Guangzhou, he further pointed out that the play is one of human basic demands, and we should study the science of the play, grasp the technology of the play and develop the art of the play. The play is the leisure, and the culture of the play is the leisure culture. In 1995, under his supports, the first leisure culture design center was founded in China, which further drove the rise and development of Chinese leisure culture (Ma, 1996, P.157-158).

Mr. Yu Guangyuan thought that when part of time in off hours were used in "leisure", most people would feel easier in their leisure activities, i.e. the leisure was decided by the character of the activity which made people amused (Yu, 2002, P.41-43). 
In the book of "the leisure time view", Pang Yaohui thought that "the problem of the leisure time is an important social problem, and many problems such as how to make the time budget, how to scientifically utilize time, how to create conditions and properly increase leisure time, how to eliminate the useless consumption of the leisure time and develop the potential of the leisure time, and how to predict the leisure time and design the leisure culture should be urgently studied by us (Pang, 1985, P.16-17)".

From above foreign and domestic scholars' discussions about the meaning of the leisure, we thought that the leisure mode every man selects should accord with the individual personality, scientifically predict whether his favorite leisure mode, especially for the sports leisure mode, can bring physical and spiritual release and pleasure or directly or potentially influence complete development, and it is the effective approach and method for the leisure main body actively uses the healthy leisure mode to achieve the optimal opportunity and enhance individual quality, reduce the large pressure of the individual survival pressure, and reply the rapid development of the science and technology and quick work speed. As human leisure, the scientific attitude adopted by the leisure main body can more show the tendency of human complete development. Under the guide of scientific leisure theory, the leisure will be the important locale of the human complete and free development. In this social locale, the individual should represent the potential and quality from non-specialization and turn them into human essential power. As viewed from this meaning, the leisure is the important part in the human life process. Just as what Marx said, "the personality should be developed freely, so the necessary labor hours are not reduced for obtaining surplus-labors, and the social necessary labor should be directly reduced to the minimum, and because all people save time and create measures, the individual will develop in many aspects such as arts and science (Marx \& Engels, 1979, P.218-219)". So we think that the so-called leisure is the process that the individual scientifically select the mode suit for the personality especially by the scientifically effective and polite body-building mode in the part off-hours, and actively enhance the individual quality and scientifically and reasonably pursue the life meaning when he obtains the release and pleasure of the body and spirit. And it is not only the necessary process to make people "becoming people", but the effective locale to make the individual beneficial in the lifetime, and the activity space for human complete and sustainable development.

\section{Explanation of ecological sports leisure}

In the 21 st century, under the guidance of the developed countries, human is walking up to the time of leisure which is coming up to China building the socialism harmonious society. "The leisure time will more emphasize to fulfill human demands of spiritual culture and realize human self-development and self-value. And as the most active, interesting and beneficial leisure mode to amuse body and mind, develop friendship, maintain healthy and challenge selfhood, the sports will certainly be the important content of human leisure activity (Lu, 2005, P.360)". And many problems such as what is the leisure sports and what characteristics does the leisure sports have will certainly be the hotspot problems for the theoretic circle, especially for the sports theoretic circle. Because China is facing the leisure time and the leisure culture and the leisure sports activity is starting, so the concept of the leisure sports with consensus in Chinese sports theoretic circle. From the meanings of leisure, sports culture and human self-development, we think the leisure sport is the sports activity that human actively participate independently, freely exert the creativity, seek the release of body and mind, obtain pleasure psychological experience, continually enhance the life quality and pleasure index, and realize human complete development. Here, we know the free dominant time and independent participation is the precondition of the leisure sports, and the sports activities out the free dominant time and independent participation will not be the leisure sports. For example, some department organizes the basketball game at Wednesday, and it is the sports activity, and it is not the sports leisure, because the game is not played in employees' freely dominant time, and it is hart to ensure all employees all like the basketball and would take participate in the game. The creativity, relaxed body and mind and psychological experience are the start and the approach to enhance the life quality and the happiness index and finally realize human complete development. Human self-development and complete development is a process, and in this modern society that the information, knowledge, science and technology develop very quickly and in the living that the high efficiency, quick cadence and drastic competition are the basic survival modes, people try to walk out the condensed space and time, eliminate the feeling of anxiety, look forward to the sense of security and find back the spirit home. Therefore, the leisure and the leisure sports have been a sort of basic psychological demand for modern people. In the freely dominant time, people can independently participate and create rich and colorful leisure sports activities by their favorite mode, seek the release of body and mind, obtain charmed psychological experience, gradually enhance the life quality and happiness index, and finally realize the complete development of people. The realization of human complete development is the final object of the leisure sports, and whether for the release of body and mind, or the psychological experience, or the enhancement of life quality and happiness index, it should achieve the complete development of people, or else, the release of body and mind and the psychological experience will lose meanings, and the leisure sports will be meaningless.

From the concept, the leisure sports possess three significant characteristics, i.e. the characteristic of independence, the characteristic of happiness and the characteristics of creation. For the independent sport, whether for the dominance of the time or for the selections of measure and mode and the pursuing of the object, the leisure sports should fully reveal 
the individual independence, and it doesn't possess the characteristics of compulsion and restriction, which is the most significant characteristic different with competitive sports and school sports. The leisure sport is that human select their activities in their free time, and they can fully express their feelings and their tastes, and show their personalities and walk out the mechanization and modularization of the labor in the sports space without material gains and result restriction. Therefore, as a sort of living mode of self-selection and self-realization, the leisure sports offer uncommon opportunity and infinite space for the development and the expression of the personality, which means the sufficient independence right. For the happy sports, we can find happiness from our favorite work, study, achievement and family living, but in the real society and living, the process to look for this sort of happiness is suffering and brutal, and only in the leisure sports, human can find the release of body and mind, express the pleasure of mood, and experience the meaning of life, that means the leisure sport is the happy experience. The acquirement of happy experience in the leisure sports is decided by the participators' devotion and impetus, and more devotions will obtain stronger happy experience and achieve the "peak experience" (Maslow), at the same time, it is decided by the social interaction among participators. For the creative sports, in the leisure sports, people relax their bodies and minds, experience gladness, return the home of imagination and freely create the personality. People will hardly possess relaxed body and mind, happy experience and the air with the imagination when they don't get rid of nervous minds, worrying veins and dangerous mind frame. Without the imagination, there are not creation and innovation. When we face opening adventure and unrestricted behaviors, we can fully exert the free imagination and creativity, and feel that the sport is the activity which is dominated by human, and the leisure sport is the expression of their ideas and wills, the activity enjoyment of physical strength and potentials, and the individual self-realization, so it is the sport with imagination and creativity.

The quick development of the society and the advancement of the science and technology can bring human more abundant leisure activities than anytime in the past. Except for leisure sports, the surf the Internet, the movie and TV, the press and books, and the music and arts offer numerous leisure selections for people. We can classify the leisure sports from different angles, and from the angle of the leisure, the sports culture and the human self-development, the ecological leisure sport is the most essential and core sports mode.

"As a sort of mode to actively participate in the living, the leisure is a sort of ambit and idea, and a representation of human social civilization. In the east that the agricultural civilization is accumulated profoundly, especially in China which is the representation of east Asian civilization, the leisure possesses its own cultural characteristics, and it emphasizes the direct taste of body and mind in the nature, and it is embodied as more ecological and cultural leisure culture (Hu, 2005, P.377)".

The leisure sport has important practical meaning for the construction of the modern harmonious society. Chinese nation all along advocate the nature, devote the nature and develops harmoniously with the nature. In the ecological leisure sports time, we should use part of them to enjoy the survival materials and fulfill the physiological natural ecological demand, and at the same time, it is necessary to use quite part of time to consume the development materials and enjoy the materials, and make the human intelligence, the physical strengths and the ecological civilization accomplishment including the ecological taste and ecological quality, and even the good personality to be ecologically developed completely and freely. And it is one of effective approaches and measures to utilize the factor of the beauty, especially the factors of the ecological beauty, the sports beauty and the healthy beauty to educate people by the aesthetic feeling and taste.

Taking the ecological beauty as the object, the ecological sports leisure enjoys the ecological art beauty, perceives the natural ecological beauty, builds the manual ecological beauty, especially pursues the sports healthy beauty, and enhance the individual ecological quality and ecological ethic feeling in the dynamic process to make the leisure main body participate in the ecological system full of lives and harmonious beauty.

First, enjoy the ecological art beauty. Through the course of the civilization, the civilization is the symbol of the cultural advancement degree. For its connotation, the civilization is relative to the wildness, wildness and ignorance, and it indicates the degree of the human social advancement and the civilized status. From general meaning, the "culture" includes all results (material, spiritual, active and negative) of human activities, and the "civilization" means the active results of human activities. As viewed from the layer of getting to the root of a matter, which sort of "civilization" and "culture" can leave the natural ecology? Look up the welkin, the sun and moon shine, and overlook the earth, the mountain and river are beautiful, and human contains heroes in the universe, and human are affected by the nature, study from the universe and the nature, so the civilization is created. The natural civilization can not only be integrated in the universe, but draw near everything on earth, and the colorful literary talent, bright and beautiful grass and wood, charmed springs and stones, sounds of nature compose the picture interlaced by sounds and colors. Even the nature without any knowledge contains beautiful pictures, how about the human heart?

For the Chinese Tao, the idea is guided by the nature, and the art opinion is to take the nature as the highest taste principle, i.e. "the universe with the largest beauty is silent, and the time with definite rules discusses nothing and 
everything on earth with constant reasons speaks nothing. The saint can enjoy the beauty of the universe and understand the truth of the universe, so the holy man does nothing and the mahatma acts nothing to view the universe". Remote sky and broad earth show the great and simple ecological art beauty by the wordless form. For the taste, to enjoy the ecological art beauty is to pursue the aesthetics idea of "natural go vulture act the role offing". The beauty should be felt and experienced. And real beauty exists in the universe mixed with nature. The ecological art beauty is the "beauty of the universe", and it "possesses everything on earth and travel in the outer space, clouds and winds". The sounds of nature in the ecological art beauty root in the beauty of the nature, and it is the highest aim of the taste (Fu, 1996, P.4).

Second, perceive the natural ecological beauty. The natural ecological beauty is the product of the nature through mechanical, physical, chemical, biological and long-term self-organized evolvement, and it presents the original and wide beauty in thousands of postures, includes various sorts of biology full of vital forces and energies, and embodies the beauty of the wonderful article excelling nature. Of course, "the profound perception to the ecological beauty can not stay on the sensible forms such as exterior color, form and symmetry, but go deep into the contents of ecological rules and ethic standards relative to life and organically uniform the truth, the honest and the beauty (She, 1994, P.50-55)". The main body who takes enjoying the ecological beauty as the leisure mode can directly obtain the spiritual enjoyment, the nature of the sentiment and the enhancement of the taste, develop and cultivate scientific, healthy and massive ecological value opinion and idea, harmonious and great ecological ethic affection, and further universally enhance the individual ecological leisure sports quality and effective drive human complete development course.

To perceive the natural ecological beauty, people should respect the "specialization" of the biological survival and maintain the "ecological status" of the biological activity. Just as what German famous philosophic anthropologist Michael Landman said, "because specialized apparatus and instinct, animals are limited in the very special exterior living condition and they can survive only in the living condition. Every animal species exists in a special living space (habitat), and many animals only live in the deep of the sea, and some other animals only inhabit in boscages (Michael, 1988, P.176)". The "ecological status" also expresses the similar meaning, i.e. certain species will occupy certain status in the ecological system because of its highly specialized living mode. "Specialization" and "ecological status" remind people to perceive the natural ecological beauty, follow the natural ecological rule and implement the ecological sports leisure.

Third, build the manual ecological beauty. The manual ecological beauty is to reasonably utilize, skillfully process and properly change the nature and further enhance the original natural ecological beauty under the premise that human follow the ecological rule and the creation rule of the ecological beauty by the green science technology and ecological technical principle. It requires people actively participate in the construction of the manual ecological beauty, exert the education function of the leisure main body, and pursue the truth, the honest and the beauty on the higher layer. Here, the truth, the honest and the beauty have special meanings. "the truth is presented as the true of the natural ecological rule, and the honest is presented as human correct natural view, and the beauty is presented as the harmonious intergrowth of human and other biological species and the natural environment (Yang, 2000, P.33)".

To build the manual ecological beauty, we should specially pay attention to the "harmonious beauty" and the "energy beauty" between the biology and the environment. And the "harmonious beauty" and the "energy beauty" are just the important characteristics of the natural ecological beauty. The harmony and the energy are the value which can make the life full of vigorous vital force and sustainable life force, the whole biological system follow the material cycle, energy conversion and information communication rule, and make the natural ecological environment of the earth keep youth forever, and make the ecological leisure main body really feel the life energy and harmonious beauty integrating the nature with the body and mind, purify human natural ecological soul in the happiness enjoying high-layer ecological sports leisure, enhance human spirit ecological ambit and protect human survival environment value.

To build the manual ecological beauty, we should also strengthen the "creation beauty" and the "participation beauty", and the natural ecological beauty is built by the propagation, the microorganism and the non-biological environment together in the mutual evolvement, and the manual ecological beauty is built by the human creativity when human follow the ecological rule, and it is also the ecological resultant force formed by the human creativity and the natural creativity. The manual ecological beauty roots in the natural ecological beauty and exceeds the natural ecological beauty. The ecological leisure main bodies consciously create and participate in these manual ecological beauties, deeply experience and fully embody the creation beauty and the participation beauty of the leisure sports main bodies, for example, experiencing the tree planting in the ecological tour leisure of Inner Mongolia, participating in the activity of defending the mother river and building the Reader forest.

Finally, pursue the sports beauty. It is the practical process, the ideal aim and the highest ambit pursued by the modern human leisure culture. WHO defines the health as that the health means the integration and the goodness of the body ability, the spirit ability and the social ability. WHO thinks that the health is "the complete status of the whole body and mind and the sociality, not only the status without diseases or the weak status".

The healthy beauty standard of WHO includes proper avoirdupois, symmetric body, harmony of head, shoulder and 
stern, plump muscle, elastic skin, the hair with shines and without scurf, bright eye, acute reaction, neat teeth, the gum with normal color and luster, resisting universal colds and infections, possessing abundant energy and shouldering daily life and heavy work by easy stages without fulsome intensity and tiredness, active attitude, optimistically dealing with affairs, being willing to assume responsibilities, being good at rest, disciplinary living, being good at intelligence, strong emergency ability, adapting various changes of the exterior environment. It indicates the change of the human ecological sports mode. From the competitive sports pursuing the higher, the quicker and the stronger to the universal sports leisure, we can see the complete combination of life and beauty, see the sublimation of human spirits and see the life and hope. It possesses all meanings of human sports leisure and healthy beauty from the universal meaning. And it can undoubtedly bring the pleasure of taste for people.

\section{Ecological leisure sports and human sustainable development}

The academes usually grasp the contents, the conditions and the implementation approach of human sustainable and complete development mainly from the layers such as the transformation of the social system and the perfection of the social relationship, but they always ignore the important function and active meaning exerted by the ecological environment and the leisure especially the ecological leisure sports in human complete development, so we should give deep research and sufficient emphasis.

First, the orderly cycle and healthy operation of the ecological environment system are the natural premise and the necessary condition of human complete and sustainable development. Human is not only the survival of the nature, but also the survival of the society, and it is the opposite unification of both sides. Therefore, the nature and human have not only the adaptability, but also the inadaptability. For the adaptability, on the meaning of human biological attributes and natural existence, the nature offers the basic conditions of human survival and development, such as wide earth, clean freshwater resource, measurable light and heat conditions, feasible temperature and humidity, fresh air quality, abundant propagation resource and other various ecological environment resources, which compose the biosphere that the human survival and development can not leave all the time. If there is not the adaptability, there is no the generation of the human being, even more the development of human being. Therefore, "the human is the natural existence directly. As the natural existence with life, human possess the natural force and the life force, and human exists dynamically, and as the gifts, talents and desires, these forces act on the human, on the other hand, as the natural, material, sensible and objective existence, like propagation, human are restricted and limited, i.e. the object of human desire exists outside the human independent of the object (Marx \& Engels, 1974, P.167)". "If one existence has no its own nature outside the existence, it is not the natural existence and it can not participate in the living of the nature (Marx \& Engels, 1972)". Therefore, human should and must protect the natural ecological system.

For the inadaptability, from human social attribute and cultural existence dimension, through the human have "broken away" from the nature and been the "opposite", but they have to contact with the nature and obtain the living materials for the survival and development. However, the resources and energy sources of the earth are not infinite, and the nature will not automatically fulfill various demands of human survival and development. The nature only offers the possibility of human survival and development, but to make the possibility change to the reality, it still needs human to recognize, utilize and change the nature, and protect, construct and perfect the nature to create the value. As the opposite unification of the natural existence and the social existence, the human construct the harmonious and graceful ecological environment, which equals to construct the natural base of human survival and development, and also equals to construct the material premise of the economic and social development, and accordingly make for the valuable demand of human survival and development. By contraries, to destroy the orderly natural ecological environment equals to destroy the natural condition of human survival and development, i.e. to destroy the precondition of the economic and social development, and to deviate from the beneficial pursuit of human survival and development.

Second, the organic gestation and development of the ecological sports leisure are the effective approach and the approach dependence of human complete and sustainable development. The association of the time and human complete development had be early founded by Marx, "the time is the space of human development (Marx \& Engels, 1972, P.195)", "the time is human active existence in fact, and it is not only the size of human life, but the development space of the human being (Marx \& Engels, 1979, P.532)", "the free time is the time which can be dominated freely, and the time can not be absorbed by the direct labor, and it is used in rest and amusement to cut broad space for the free activities (Marx \& Engels, 1975, P.281-282)". Marx had highly evaluated the basic function of the free time on human complete development, and he pointed out that "the development of whole human being is to utilize the free time for the human natural existence, and the precondition of whole human development is to take the utilization of the free time as the necessary base (Marx \& Engels, 1975, 216)".

Therefore, in the leisure time, the human should create the social ecological space for them to survive and develop, especially develop and create and utilize the time-space and condition of the ecological leisure and the sports leisure, which can quicken human complete development, and make us to find the development history, existence status and future orientation of the leisure time in the social-ecological space, so we can see that the human can consciously dig 
their real essential power and actively advocate the humanism leisure mode and complete development consciousness, and it reflect the human profound understanding, deep cognition and grasp to their ecological sports mode and development mode. In the long river of human history, the leisure time actually has participated in the coagulation of all material and spiritual civilization results, and in the present and future process, the ecological leisure time will more obviously participate in human material and spiritual accumulation of the human society, especially for the ecological civilization results. So, it is not only the important measure to evaluate human self-development, but also the important parameters to measure human complete development.

From the leisure theory, human complete development is also be embodied in the saving of time, because the time distribution of various activities decides the social development degree and human development space level. Marx said, "Just as the individual, the social development, the social enjoyment and the social activity are all decided by the saving of time. And all savings are the saving of time in the final analysis (Marx \& Engels, 1979, 120)". On the other side, to reduce the necessary labor time and increase the free leisure time equal to expand the space of the individual and the social development. Therefore, it is not only the symbol of social advancement, but also the basic premise, necessary condition and important guarantee to promote human complete development.

Third, the sustainable cultivation and enhancement of the environment protectable ecological quality is the implementation condition and the important guarantee of human complete and sustainable development. As before, the ecological leisure sport is the activity mode that the leisure main bodies enjoy the ecological art beauty, perceive the natural ecological beauty, build the manual ecological beauty and pursue the sports beauty, i.e. the leisure mode on the higher layer that the leisure main bodies take the ecological beauty as the leisure objects, and effectively cultivate and completely enhance human ecological quality through this leisure mode, and drive the course of human ecological civilization and promote human complete development.

We think that the ecological quality is the interior of human being which takes the ecological world view and the ecological methodology as the core, takes the ecological value view and the ecological ethics as the references, and takes the ecological thinking mode and the ecological behavior criterion as main contents and representation form. It embodies the main composing of present and future human quality and the dominant tendency of human complete development. In the new century, the ecological development of the productivity, the optimal perfection of the ecology and the free and complete development of human being all can not leave the effective enhancement of human ecological quality and the sustainable development of human ecological civilization. With the continual increase of human leisure time, especially the ecological leisure sports time, and the gradually development of the leisure space, especially the ecological leisure sports space, the human being is obtaining complete and sustainable development in the process continually utilizing, enjoying and creating the ecological leisure sports.

\section{References}

Fu, Daobin. (1996). Singer's Paradise: the Naturalism Spirit of Chinese Culture. Harbin: Northeast Forestry Press. P. 4. Geoffrey Godbey, interpreted by Kangzheng. (2000). Leisure in Your Life. Kunming: Yunnan People's Publishing House. P. 14.

Geoffrey Godbey, interpreted by Zhang, Chunbo et al. (2000). Leisure and Leisure Service in the 21st Century. Kunming: Yunnan People's Publishing House. P. 133.

Hu, Xiaoming. (2005). Theory of Well-off Society Sports Leisure and Amusement. 2005 National Sports Development Strategy Seminar Corpus. Beijing: Beijing Sports University Press. P. 377.

Johan Kelly, interpreted by Zhaoran. (2000). Making for Freedom: New Theory of Leisure Sociology. Kunming: Yunnan People's Publishing House. P. 22, 104.

Lu, Yuanzhen. (2005). The Strategy that China Enters into the Leisure Time and Develops Sports Population. 2005 National Sports Development Strategy Seminar Corpus. Beijing: Beijing Sports University Press. P. 360.

Ma, Huidi. (1996). Leisure: Building the Beautiful Spiritual Family for Human Being. Xinhua Digest. No. 12. P.157-158.

Marx \& Engels. (1975). Karl Marx and Frederick Engels (Volume 26(3)). Beijing: People's Publishing House. P.281-282, 216.

Marx \& Engels. (1974). Karl Marx and Frederick Engels (Volume 42). Beijing: People's Publishing House. P. 167.

Marx \& Engels. (1979). Karl Marx and Frederick Engels (Volume 46). Beijing: People's Publishing House. P. 120, 218-219, 532.

Marx \& Engels. (1972). Karl Marx and Frederick Engels (Volume 2). Beijing: People's Publishing House. P. 195.

Michael Landman. (1988). Philosophical Anthropology. Shanghai: Shanghai Translation Publishing House. P. 176. 
Pang, Yaohui. (1985). The Leisure Time View. Xinhua Digest. No.7. P. 16-17.

She, Zhengrong. (1994). Philosophical Consideration about the Ecological Beauty. Studies in Dialectics of Nature. No.8. P. 50-55.

Yang, Guihua. (2000). Ecological Tour. Beijing: China Higher Education Press \& Springer Press. P. 33.

Yu, Guangyuan. (2002). For Society Where Leisure is Enjoyed by All. Studies in Dialectics of Nature. No.1. P. 41-43. 